\title{
READING IN THE ELEMENTARY SCHOOLS OF INDIANAPOLIS, IV
}

\author{
WILLIAM S. GRAY \\ School of Education, University of Chicago
}

THE BROADENING OF EXPERIENCE THROUGH EXTENSIVE SILENT

READING (FOURTH, FIFTH, AND SIXTH GRADES)

By the time a pupil enters the fourth grade he should be able to read fluently subject-matter of ordinary difficulty, such as untechnical articles in high-grade newspapers. The extent to which he comprehends what he reads depends primarily on the fund of information which he has at his command. The pupil of limited experience in a given field will comprehend what he reads less thoroughly than one who has had wide experience along relevant lines. Inasmuch as the average pupil secures most of his experiences concerning the world at large through reading, rapid progress in the development of ability to comprehend depends to a very large extent on extensive reading. This conception of the reading problem in the intermediate grades is fundamentally different from the traditional point of view. As a rule no new problems have been introduced, but the reading problem of the lower grades has been enlarged and intensified in the higher grades. The subject-matter has been more difficult, articulation and expression requirements have been more exacting, and discussions have been more detailed and analytical.

The problem of reading in the intermediate grades, as it is here presented, relates primarily to the acquisition of experiences through silent reading. The justification for this change in emphasis from oral reading to silent reading may be briefly 
stated as follows: A first-grade pupil is able to pronounce words more rapidly than he is able to recognize them, but during the second and third grades his rate of recognition equals or surpasses his rate of pronunciation. By the time the pupil reaches the fourth grade he has mastered the art of reading well enough to use it independently. The result is that he begins to read more rapidly than during the earlier grades. $\mathrm{He}$ becomes interested in the content of what he reads, and; because his vocal chords react somewhat slowly, his eyes run along the lines more rapidly than he can pronounce the words. It is evident that under these conditions speed in recognition becomes an enemy of excellence in oral reading. These facts justify the contention that less emphasis should be given to oral reading during the intermediate grades and greater opportunity should be given for the development of effective habits of silent reading. Further justification for this change of emphasis is found in the fact that a fourth-grade pupil of average ability has usually mastered the mechanics of reading so well that he is able to pronounce at sight words which he is unable to understand. Whenever a pupil has reached this stage in his development, additional mastery of word pronunciation is less important than increased mastery of meanings. These meanings are best secured by the pupil's coming in contact with words and sentences time after time until a body of meaning is built up in regard to them. A large quantity of reading with emphasis on the thought-side such as was recommended for the second and third grades aids greatly in the development of meanings. The change of emphasis from oral reading to silent reading in the intermediate grades gives added opportunity for concentrating attention on the content of what is read.

Again, the curves of progress for rate of silent reading as shown in Diagram VIII $^{1}$ reveal the fact that progress in rate

${ }^{1}$ The diagrams referred to in this article appeared in the February number of the Elementary School Fournal. 
of reading is very rapid in the second and third grades, is less rapid in the intermediate grades, and approaches a maximum in the sixth and seventh grades. Numerous investigations of progress in reading show that by the time pupils reach the sixth grade their habits of careful silent reading have been more or less permanently established. It is evident, therefore, that the intermediate grades represent a period during which the rate of reading may be emphasized to advantage. If rate is not emphasized until later, it is probable that improvement in rate, if secured at all, will be attained only through the expenditure of much more time and effort than is required during the intermediate grades.

The foregoing discussion emphasizes the fact that progress in the acquisition of reading ability is dependent on the extension of the pupil's field of experience through extensive silent reading. This is necessary in order to gain a broader background for more comprehensive and critical interpretations. Every content subject in the curriculum should contribute generously to this phase of the pupil's development. Co-ordinate with this large emphasis on meanings and experiences are several phases of the technique of reading which should not be neglected. The effective reader is the one who can read rapidly as well as intelligently. Training in the recognition of increasingly large units is a prerequisite of rapid silent reading and should not be neglected. Furthermore, the extensive silent reading which the pupil now undertakes brings him into contact with words whose meanings and pronunciations are unfamiliar. Thoroughgoing instruction should develop ability on the part of pupils to determine the meanings of such words through the use of appropriate helps.

The preceding paragraphs have set forth some of the general considerations relating to reading instruction in the intermediate grades. If Indianapolis adopts the program as outlined above, it follows that the most urgent problems in reading 
must be defined in the light of the present achievement of the pupils. The reading tests which were given revealed the following facts in regard to the results of reading instruction in the fourth, fifth, and sixth grades: (I) The results in oral reading were somewhat lower than in the case of several cities with which Indianapolis was compared. (2) The rate of oral reading was below the average in the fourth grade, but approximated the average from that point on. (3) Accuracy in oral reading was distinctly low throughout the intermediate grades both in simple and in difficult passages. (4) The rate of silent reading was somewhat below the average in the fourth grade, but rose to a high level in the fifth and sixth grades. (5) The comprehension scores were noticeably low throughout the intermediate grades.

Owing to the slow progress which has been made in the lower grades of some schools it will be necessary to give considerable time to oral reading in the fourth grade. Wherever continued emphasis on oral reading is necessary, quantitative sight reading of simple selections is recommended. Fourthgrade teachers who find themselves confronted with this problem should read the preceding section of the report for detailed suggestions concerning methods of mastering the mechanics of reading. When pupils reach the point, however, at which they are able to read fluently and to group words effectively, the teacher has objective evidence that emphasis may appropriately be changed from oral reading to silent reading. After the present year continued emphasis on oral reading in the fourth grade should be unnecessary.

The low comprehension scores which were made by pupils of Indianapolis suggest the need of effective training in habits of thoughtful silent reading. There are four prerequisites to rapid progress along this line: namely, an abundance of interesting material for reading, concentration of attention on the content of what is read, improvement in rate of reading or 
enlargement of the units of recognition, and development of ability to determine the meanings and pronunciations of new words through the use of appropriate helps. Each of these prerequisites will be discussed in turn.

An abundance of interesting reading material is necessary both for the wide extension of reading experience and for the development of ability to attach meanings to words. The principles underlying the selection of appropriate subjectmatter for reading are discussed in detail in a later section and will not be commented on here. The fact of immediate importance in this discussion is that interesting and appropriate selections must be provided in abundance for each class in reading. Instead of devoting days to the re-reading of one selection, the pupils should read pages and in many cases entire chapters during the course of each reading exercise. The content subjects as well as the reading exercise should contribute generously to the rapid enlargement of the pupil's fund of information. Instead of devoting an entire recitation period to the discussion of two or three pages concerning the discovery of America, teachers can secure far better results if the pupils are permitted to read chapters or even entire books which give interesting accounts of this historic event. Furthermore, reading outside of class hours should be encouraged in every way possible. In many schools throughout the country pupils are required to read at least one book a week in addition to the readings which are assigned in class. This requirement presupposes an abundance of reading material for use by the pupils. The fact that ample provision of appropriate books has not been made will be discussed later. If Indianapolis is to realize the most desirable results from instruction in the intermediate grades, reading material must be supplied in greater abundance for use both in the classroom and for outside reading.

Attention is concentrated on the content of what is read during silent-reading exercises in various ways. One of the 
typical exercises observed in Indianapolis was conducted as follows: The teacher directed the pupils to read the first paragraph silently. The time allowed for reading the paragraph was limited. After the paragraph had been read, the pupils were asked to reproduce what was remembered or to answer questions based on the passage. In many cases these discussions were detailed and analytical. This method is evidently based on the assumption that silent-reading ability is dependent primarily on some sort of technique that can be developed by exercising the memory or by training pupils in the art of breaking up a passage into small units of thought. While pupils undoubtedly need training along these lines, nevertheless a wide use of exercises of this type limits the opportunity for extensive reading and for the enlargement of experience, both of which are of the greatest importance in training pupils to understand what they read.

The exercise which follows was observed in one of the schools of St. Louis. It is discussed at this point because it illustrates a type of silent-reading lesson which secures a large quantity of information and which trains in effective methods of silent study.

The teacher was conducting a series of information lessons concerning Holland. She had secured a large number of books which contained relevant chapters. The pupils were given two reading periods in which to read as much as they could silently and to make notes in regard to the interesting points which they discovered. At the end of this period the teacher and the class made a list of the most important problems relating to Holland. Each pupil chose a problem from the list and made it the basis for further study. He read carefully but rapidly all of the references which he could find relating to his problem. Pictures were secured, illustrative materials of various types were collected, and the facts which were secured through reading were organized in good form. After two days of intensive study of this type each pupil reported to his classmates the results of his reading and study. Whenever necessary, references were read to the class to illustrate an important point or to give support to a judgment expressed by the pupil in regard to some phase of life in Holland. 
It is evident that exercises of this type provide for the enlargement of experience, give ample opportunity for extensive reading, concentrate attention effectively on the content of what is read, and train in the careful selection and organization of subject-matter. Frequent exercises of a similar character are recommended for Indianapolis in place of unproductive oral-reading exercises and in place of some of the detailed silent-reading exercises which were observed.

It should not be understood that all silent-reading exercises are to be conducted according to the plan outlined in the preceding paragraph. Effective readers read at different rates and for different purposes. For illustration, one may read the morning newspaper to determine what the important events are which have occurred recently. Interesting reading habits have been developed by most good readers in such cases. The eyes take in the large headlines almost instantly, and certain columns are selected for reading. The eyes run down a column rapidly, catching items of information here and there. After a very short period, attention shifts to another column, and the skimming process continues. In two or three minutes an effective reader has secured a very large number of important news items. Again, one reads a popular novel rapidly for pleasure, dwelling upon those parts which appeal to one's interest. On the other hand, an article in the Atlantic Monthly dealing with some modern social problem requires more deliberate reading. One may read slowly in such cases, pausing at each sentence or line. Often each statement is carefully weighed and a judgment reached in regard to its validity. The significant point which arises out of the foregoing discussion is that there are several silent-reading attitudes, each with its set of appropriate habits. No single device for teaching silent reading will lead to the establishment of all the types of reading habits with which a reader should be equipped. Each teacher should select materials from time to time which will give opportunity 
for development along various lines. The pupils should be trained to recognize at once the type of selection which is to be read and to associate with it the appropriate reading attitude and habits.

As was pointed out earlier in the discussion, progress in silent-reading ability involves an enlargement of the units of recognition. Scientific studies have shown that the reader of average ability uses only a part of the possibilities of recognition which are supplied by his field of clear vision. An enlargement of the units of recognition demands broad experiences which make possible the comprehension of meaningful phrases in a single fixation of the eyes, freedom from the difficulties which new and unfamiliar words present, and freedom from the limitations of vocalization. It is evident, therefore, that pupils of the intermediate grades must be given frequent opportunity to read silently material which is relatively easy for them if rhythmical movements of the eyes are to be developed in which a relatively wide unit of the line will be perceived and comprehended at each fixation.

Indianapolis secures improvement in rate of silent reading by conducting numerous exercises in which the pupil is given a limited amount of time to complete a passage. This type of exercise accomplishes desirable results, as evidenced by the relatively high score made by Indianapolis in rate. The value of this method lies in the fact that it causes the pupil to utilize all of the resources at his command in order to meet the requirements which are imposed on him. Inasmuch as rate is retarded when comprehension difficulties are encountered, it is evident that units of recognition will be enlarged more quickly if simple selections are used. In addition to the exercises described above, simple selections of considerable length should be assigned for rapid silent reading in order to provide ample opportunity for the permanent establishment of effective eye movements. 
The results of the reading tests showed that the pupils of Indianapolis are very inaccurate in reading simple passages as well as more difficult ones. Thoroughgoing training in the phonetic analysis of words together with quantitative oralreading exercises in the second and third grades will do much toward eliminating inaccuracies in the reading of simple selections. The development of ability on the part of pupils in the fourth, fifth, and sixth grades to pronounce long words quickly and accurately requires more attention than is given to this problem in the average classroom at the present time. The analysis of words which was begun in the first grade and continued through the second and third grades should be extended in the intermediate grades to include the laws of syllabication and accent, and a study of prefixes, suffixes, and roots. In this connection the meanings of words as well as their pronunciations should be made the basis of intensive study. Special periods should be devoted to these problems for the purpose of developing a considerable degree of ability in the recognition of meanings and pronunciations. Meanings should be derived primarily through word analysis and through the context of what is read. Furthermore, pupils should be trained to use dictionaries and books of reference whenever such helps can be used to advantage.

The facts presented in the preceding paragraphs should emphasize the importance of both speed and quality of silent reading. During the intermediate grades selection after selection should be assigned and pupils trained to read silently under the guidance of specific purposes. Such recitations cannot be conducted without careful thought and preparation. The specific methods used must be adapted to the selection at hand, or selections should be chosen which are adapted to given purposes. Many selections can be read quickly for the story. Several pages of Black Beauty may be read quickly to find out the number of things that Black Beauty had to become 
accustomed to in order to be a well-trained horse. Speed can be encouraged by limiting the amount of time given to the reading. On the other hand, many selections should be read with more care in order to determine what are the essential points in the selections, or to weigh the relative importance of the facts, or to associate the facts with what one already knows.

Although the broadening of experience in the intermediate grades comes primarily through extensive silent reading, nevertheless it is recognized that occasional oral-reading exercises may be introduced to advantage provided they are properly conducted. It is a frequent practice in many classrooms throughout the country to organize oral-reading exercises around selections which the pupils have read three or four times during the study period and which have been discussed at length by the class as a whole. It is needless to say that such exercises usually result in little progress, for there is no real motive for reading and very few incentives to cause pupils to put forth effort. Formal exercises of this type were observed in Indianapolis. On the other hand, many teachers were observed who organized oral-reading exercises in which there were real audience situations and in which effective incentives were employed. Although teachers of the latter type usually devote far less time to oral reading than do teachers who follow traditional methods, nevertheless the results which they secure are distinctly superior. It is reasonable to assume that the pupil who puts forth his best efforts in the thorough preparation of one selection which he will read with a real purpose will make more progress than the pupil who reads several selections in fulfilling a formal classroom requirement.

At a conference which was held with several training teachers of Indianapolis a list of the most effective oral-reading devices which are used in the city was submitted by the 
teachers. They are presented here with the recommendation that they be substituted for the formal unproductive types of oral-reading lessons which are characteristic of many classrooms.

I. Each row of a class may be provided with a separate story. The readers then feel under obligation to read effectively for the benefit of their audience.

2. Rows are given charge of morning exercises. The better pupils are asked to read, and the poorer readers recite poems or are assigned very short reading exercises. As the poorer readers gain confidence they are given longer assignments.

3. Effective results are secured by having various members of a class read passages in support of a judgment which they are defending.

4. In subject-matter studies, such as history and geography, the pupils frequently read clippings from magazines and selections from books which are not accessible to all of the class, but which throw light on the problems under consideration.

5. If the pupils vary widely in ability, short selections may be assigned which are adapted to the varying abilities of the pupils. The selections may then be read during a special class exercise.

6. Good results are sometimes secured by requiring a certain degree of excellence in oral reading before the pupils are permitted to participate in a group exercise, such as a dramatic presentation.

7. A given topic, such as patriotism, may be chosen as the center of discussion and study. Newspaper clippings, poems, and prose selections may be chosen which contribute to the theme in question, and they may be read in a class exercise by individual members of the group.

8. Civic clubs may be organized to meet once a week for a period of thirty minutes. Members may be required to choose selections which are appropriate for the program of the day and to read them before the group. Each pupil has a real purpose for reading, and the audience situation which confronts him calls forth his best effort.

9. Outside-reading days may be arranged once a week in which pupils read short portions of interesting stories which they have been reading at home. Surprise-stories days may be similarly conducted.

Io. Magazine clubs are organized in some schools and the members of the club are given opportunity once a month to read articles from magazines which seem interesting or worth while to them. 
II. Some pupils prepare scrapbooks in geography known as books of travel. They secure permission to read selections from these books at appropriate times in the development of a geographical topic.

There is special need of introducing frequent tests and measurements of reading ability in the intermediate grades. It has already been pointed out that these grades are confronted with a number of specific problems, such as the rapid extension of experience through reading, improvement in ability to comprehend what is read, enlargement of the span of recognition, and improvement in oral-reading ability. Steps have already been taken in many classrooms to secure progress along one or more of the lines mentioned above. Intelligent direction of instruction requires that the teacher make frequent critical studies of the results which are secured in order to determine the lines along which progress has been made and the lines which require added attention.

Furthermore, teachers consciously or unconsciously emphasize certain phases of instruction more than others. This fact is illustrated clearly in the silent-reading results for Indianapolis, in which rate ranks high and quality ranks low. Differences in emphasis along another line are evidenced in Diagram VII, which shows different degrees of accuracy in oral reading attained by various schools. Inasmuch as wide variations in progress are possible, it is essential that a teacher determine from time to time the character of the progress which her pupils are making in order that she may know where emphasis is most needed.

Again, pupils in the intermediate grades vary widely in reading ability. Some pupils are very capable readers, while other pupils need a great deal of individual instruction. Furthermore, some pupils are weak along some lines and strong along others. Frequent tests are necessary in order to help the teacher discover the individual needs of pupils. It is true that every classroom teacher devotes a large portion of her 
time trying to determine the kind of help which various pupils need. Tests are designed to help the teacher secure the information which she needs more quickly and more accurately than she otherwise would be able to secure it.

The discussion of reading in the fourth, fifth, and sixth grades may be summarized as follows:

I. The fundamental purpose of reading in these grades is to broaden the experience of pupils through extensive silent reading. In addition there are problems in the technique of reading which should not be neglected.

2. The change in emphasis from oral reading to silent reading is justified by a number of psychological changes which occur before or during the intermediate grades.

3. Owing to the slow progress which has been made in oral-reading achievement in several schools, it may be necessary during the present year to give considerable attention to oral reading in the fourth grade. After this year major attention to oral-reading instruction should be limited to the first three grades.

4. The prerequisites to rapid progress in the development of effective habits in silent reading are an abundance of interesting material for reading, concentration of attention on the content of what is read, improvement in the rate of reading, and development of ability to determine the meaning and pronunciation of words through the use of appropriate helps.

5. There is need of providing interesting and appropriate reading material in greater abundance both for class purposes and for outside reading.

6. A larger variety of effective methods should be employed to concentrate attention on the content of what is read. Such exercises should provide for the enlargement of experience, give ample opportunity for extensive reading, and develop the various types of reading attitudes and habits which are characteristic of effective readers. 
7. Frequent rapid silent-reading exercises are necessary to enlarge units of recognition. Easy selections should be used for this purpose.

8. Whenever oral-reading exercises are conducted, they should be organized about real audience situations and they should provide sufficient motive to secure effective effort. The numerous formal oral-reading exercises of the intermediate grades should be discontinued in favor of a few well-motivated productive exercises.

9. Tests of various phases of reading ability should be given frequently in order to reveal to teachers the direction of growth, the amount of attention required for the various phases of reading instruction, and the individual needs of pupils to the end that instruction may be more intelligently and effectively directed.

THE INDEPENDENT APPLICATION OF READING ABILITY TO ALL PHASES OF SCHOOL WORK (SEVENTH AND EIGHTH GRADES)

The problem of reading in the seventh and eighth grades is very little different in kind from the problem of the intermediate grades. The pupils of the upper grades, however, should be able to read more easily and intelligently than the pupils of the lower grades. By the time a pupil reaches the seventh grade he should have acquired a broad reading experience, he should be able to read orally or silently any material of moderate difficulty, he should have developed effective habits of rapid silent reading, he should be able to recognize quickly the importance of the material which he is reading and to make use of appropriate sets of reading habits, and he should be somewhat skilful in the use of effective helps whenever difficulties relating to meaning and pronunciation are encountered. Progress in reading in the seventh and eighth grades is secured primarily through the independent application of reading ability to all phases of school work. The 
problems which arise will be discussed briefly under three headings: (a) the kind of reading opportunities which should be provided, (b) the development of effective habits of study, and $(c)$ the development of ability to make comprehensive and critical interpretations.

Pupils of the seventh and eighth grades are rapidly developing interest in social and vocational problems. The extent to which they are intelligent about these problems and the extent to which they develop an interest in their further study depend largely on the opportunity which the school provides for experience in these fields. In the past, reading in the seventh and eighth grades has been limited to a few choice pieces of literature. Pupils of these grades should read extensively in the field of literature, from which they should receive interesting information as well as pleasure. In addition to selections of this type, pupils should read widely in each of the content subjects which are studied. They should be introduced to the valuable contributions which reading along various lines makes to the field of their vocational interests, and they should develop a permanent interest in reading and discussing current events. Too much emphasis cannot be given to the need of providing abundant opportunity for pupils to read current literature and selections bearing on modern social and civic problems and on topics of vocational interest.

Training in the use of books and in effective methods of study should receive a large amount of attention in the seventh and eighth grades. Among the problems which should be considered in this connection are the following: (I) realization by the pupil of a definite goal toward which to work or a definite problem which he is to solve during the course of his reading; (2) training in the consideration of and the selection of sources of help; (3) training in the use of tables of contents, indexes, etc.; (4) practice in the orderly setting down of those 
points which are relevant to the problem at hand and in the organization of these materials for effective use in the future; (5) practice in the interpretation of the facts secured through reading and in the making of inferences from them; (6) practice in checking one's own thinking by comparison with the thinking of others; (7) introduction of new sources of help and new types of material from time to time in order to extend the possibility of independent study. These problems and many others similar to them should receive persistent attention during the intermediate and grammar grades to the end that pupils may leave the eighth grade thoroughly prepared to carry on many types of reading independently, intelligently, and effectively.

Pupils of the seventh and eighth grades should be trained to make keen and critical interpretations of the materials which are read. If the recommendations which are offered in previous sections of this discussion are followed, pupils should enter the upper grades with a very wide reading experience. This experience is one of the first prerequisites to the development of ability to make critical interpretations. In addition it will be necessary for pupils to develop the habit of using appropriate helps, such as encyclopedias and books of reference, whenever they can be used to advantage. In this connection attention should be called to an error which is made in the intensive study of selections. Too frequently the teacher requires the pupils to look up every possible reference and to study the meaning of each sentence in detail. Better results would be secured if the pupils were required to make fewer interpretations. These should be made concerning major issues in a selection, and they should be made only after the pupils have been given sufficient information concerning the points at issue to enable them to make accurate and intelligent interpretations. 


\section{SUPERVISION OF READING}

The supervision of reading in Indianapolis has been largely of a personal character in the past. Principals and supervisors have visited classrooms frequently and have offered such suggestions as their judgments dictated. Group meetings have been conducted in which the problems of the various grades have been discussed in detail. Suggestions growing out of effective classroom practices have been systematically collected and distributed to the teachers. The results secured through such agencies by the supervisors are commendable and justify the expenditure of much time and effort along these lines in improving instruction. The results of this investigation show clearly that Indianapolis has teachers of reading who are doing work of superior quality. The methods employed by these teachers should be made the subject of careful observation and study throughout the city. Teachers' meetings should be organized and demonstration lessons should be arranged in order to facilitate the study and discussion of effective methods of teaching reading.

Furthermore, a well-organized campaign should be conducted by the supervisors to promote study and investigation along each of several important lines. It has already been pointed out that there is wide variation in the point of view which teachers hold in regard to the most important outcomes of reading instruction in each grade. A number of general conferences should be held with the teachers in order that this problem may be given careful consideration. In this connection it should be said that each teacher not only ought to know the specific aims of teaching reading in her own grade, but in addition she should realize fully just what the general outcomes of reading instruction are in the elementary school. Without a clear knowledge of what has preceded and of the problems which demand further emphasis it is impossible for a teacher of a given grade to adapt instruction effectively to 
the needs of her pupils. Several other problems should be made the subject of similar study and group discussion; namely, the quantity and character of the reading material for each grade, methods of meeting the needs of individual pupils, the emphasis which should be given to oral and silent reading respectively, the most effective methods for securing progress in silent-reading instruction, methods of measuring progress in reading achievement, standards of accomplishment, etc. Rigid uniformity is not a desirable outcome of discussions of this type. They should be conducted in such a way, however, that each teacher will receive a large amount of help from the combined experience of his professional associates.

The results of instruction should be frequently measured. This point has been emphasized in preceding sections of the report. The principals of Indianapolis devote a great deal of time each year to giving individual tests of reading. The usual method which is employed consists of an oral-reading test in which the principal expresses judgment concerning the quality of the pupil's reading on the basis of certain subjective standards which he has in mind. It is evident that such a method of testing is open to numerous limitations among which are the following: (I) oral expression usually receives first consideration; (2) numerous phases of reading ability receive little or no consideration; (3) standards of judgment vary widely in different schools; and (4) the requirements in a given school vary from time to time inasmuch as subjective standards fluctuate widely. In place of the yearly test which is now given in the schools of Indianapolis, frequent tests are recommended which will secure for the supervisors and teachers information which is more objective and precise. The tests should be so organized that all of the important phases of reading ability will be examined from time to time in order that a clearer insight and a truer perspective of the reading problem may be secured. 
Furthermore, it is necessary that objective standards of accomplishment be established for the city as a whole in order that teachers may know more definitely what is expected of them and in order that promotions may be made on a more uniform and objective basis. Certain tentative standards in oral reading and in silent reading were recommended in previous sections of this report. It is possible that these standards are too high or too low for Indianapolis under the conditions which prevail in the schools at the present time. Frequent tests given during the year and at the end will aid in the determination of appropriate levels of accomplishment which should be attained by the different grades. Teachers as well as supervisors should participate in this work, inasmuch as tests reveal most to those who give them. Each teacher should become familiar with methods of giving tests. She should utilize them frequently in examining her work to find sources of strength and weakness. Through the co-operation of teachers and supervisors progressive revisions in standards and in methods of procedure can be made. This type of cooperation is necessary in order that the most productive expenditure of time and effort in reading instruction may be secured. It is only when all of the units of a school system work consistently toward clearly defined ends that the most effective results can be attained.

Indianapolis has an unparalleled opportunity to introduce frequent objective studies of reading as a permanent part of the work of the school officers and teachers. Thirty normalschool students have been trained to do such work effectively. It is recommended that these young women give tests frequently during the year in order to secure valuable information concerning the work in each school and in order to familiarize the teachers with the technique of giving tests. The scope of this work should be limited at first. Oral-reading tests can be given to advantage in the first three grades, and silent-reading 
tests can be given in all grades above the first. Teachers should give simple group tests at first. Later more exact tests should be introduced with the help of those who have been trained to give them. These tests should supply a body of detailed information concerning the reading habits, the progress, and the achievement of pupils which usually passes unnoticed in the ordinary classroom but which can be used to advantage in a progressive reorganization of methods of teaching reading.

In closing, one final recommendation is offered. Teachers throughout the country are realizing more clearly than in the past the importance of effective instruction in silent reading. Inasmuch as this phase of reading has received a relatively small amount of attention in the past, very few suggestions are available concerning the most effective methods of securing results. The type of information which is needed throughout the country can be obtained best through the co-operative effort of a large number of teachers. Indianapolis has an opportunity to make a most valuable contribution this year concerning effective methods of teaching silent reading. To this end it is recommended that the teachers of the intermediate grades, aided by the supervisors, undertake a thoroughgoing study of the problem. Group conferences will be necessary at the outset in order to discuss the various methods of instruction which are now in use. Descriptions of the most promising methods should be prepared and distributed to the teachers. Frequent tests of the results should be made. As rapidly as effective methods are determined they should be substituted for many of the formal exercises now widely used in Indianapolis. 